Jurnal Teknologi Informasi dan Ilmu Komputer (JTIIK)

Vol. 6, No. 3, Juni 2019, hlm. 229-348

INDEKS NAMA PENULIS

\begin{tabular}{|c|c|}
\hline \multicolumn{2}{|l|}{ A } \\
\hline Abdul Jahir & 235 \\
\hline Aditya Rachmadi & 315 \\
\hline Admaja Dwi Herlambang & 315 \\
\hline Ahmad Afif Supianto & 341 \\
\hline Ahmad Lutfi Bayu Aji & 335 \\
\hline Alam Rahmatulloh & 327 \\
\hline Andi Nur Rachman & 327 \\
\hline Ari Kusyanti & 301 \\
\hline Azifatul Istna Hanifah & 287 \\
\hline \multicolumn{2}{|l|}{ B } \\
\hline Bagas Ryant Setiawan & 245 \\
\hline Bayu Priyambadha & 229 \\
\hline \multicolumn{2}{|l|}{$\mathrm{C}$} \\
\hline Christina Deni Rumiarti & 245 \\
\hline Cindy Felita Nur Alimah & 315 \\
\hline \multicolumn{2}{|l|}{ D } \\
\hline Darius Antoni & 257 \\
\hline Dedin Anike Putra & 287 \\
\hline Deny Hari Prasetya Dewa & 335 \\
\hline Defri Kurniawan & 277 \\
\hline Dian Puspita Hapsari & 321 \\
\hline \multicolumn{2}{|l|}{$\mathbf{E}$} \\
\hline Edi Supratman & 257 \\
\hline Eko Budi Susanto & 295 \\
\hline Eko Sakti Pramukantoro & 335 \\
\hline \multicolumn{2}{|l|}{$\mathbf{F}$} \\
\hline Fahmi Anwar & 327 \\
\hline Fajar Pradana & 229 \\
\hline Falih Farhan & 341 \\
\hline Fandi Arianto & 321 \\
\hline Fariz Andri Bakhtiar & 335 \\
\hline Fatoni & 257 \\
\hline \multicolumn{2}{|l|}{ I } \\
\hline I Dewa Made Pranata Wiana & 245 \\
\hline I Putu Pradnyana Iswara & 341 \\
\hline Indriati & 301 \\
\hline \multicolumn{2}{|l|}{$\mathbf{K}$} \\
\hline Kuat Indartono & 235 \\
\hline \multicolumn{2}{|l|}{ M } \\
\hline Mochmmad Adhy & 229 \\
\hline Moh. Reza Maulana & 295 \\
\hline Muhammad Dimas Setiawan Sanapiah & 287 \\
\hline
\end{tabular}


Jurnal Teknologi Informasi dan Ilmu Komputer (JTIIK), Vol. 6, No. 3, Juni 2019, hlm. 229-348

\begin{tabular}{|l|r|}
\hline N & \\
\hline Nanang Fakhrur Rozi & 321 \\
\hline P & 295 \\
\hline Paminto Agung Christianto & 309 \\
\hline R & 277 \\
\hline R.M. Nasrul Halim & 295 \\
\hline Ramadhan Rakhmat Sani & \\
\hline Restyandito & 267 \\
\hline S & 315 \\
\hline Sarjon Defit & 267 \\
\hline Satrio Hadi Wijoyo & 287 \\
\hline Supratman & \\
\hline T & 267 \\
\hline Tri Afirianto & \\
\hline V & 341 \\
\hline Vitriani & \\
\hline W & \\
\hline Wira Kumara & \\
\hline
\end{tabular}




\section{INDEKS KATA KUNCI}

\begin{tabular}{|c|c|}
\hline $\mathbf{A}$ & \\
\hline ADHD & $301-302,305-307$ \\
\hline Ajax & $327-328,330-331$ \\
\hline Akademik & $257-266$ \\
\hline Analisis sentimen & $321-322,325$ \\
\hline Android & $\begin{array}{r}235-236,238,241,243- \\
244\end{array}$ \\
\hline Apilkasi Mobile & 287 \\
\hline AR.js & $295-296,299$ \\
\hline Arduino & $\begin{array}{r}235-236,238,240,243- \\
244\end{array}$ \\
\hline Authentication access control & $235-236,238$ \\
\hline Authenticity & 295 \\
\hline B & \\
\hline Batik & $295-299$ \\
\hline Blackbox testing & 277 \\
\hline C & \\
\hline Cyber campus & $267,269-270,274-275$ \\
\hline D & \\
\hline Decision tree & $341-344,347-348$ \\
\hline DeLone and McLean Model & 315,319 \\
\hline Detector & 295 \\
\hline $\mathbf{E}$ & \\
\hline EAP & $257-261,264$ \\
\hline Eksekutif & $257-266$ \\
\hline E-label batik & $295-299$ \\
\hline End-to-end security & $335-336,338-339$ \\
\hline Ensemble Classifier & $301-303,305-306$ \\
\hline Evolusi perangkat lunak & $229-230,233$ \\
\hline H & \\
\hline Hybrid Cuckoo Search & $321-323,325$ \\
\hline I & \\
\hline ICT Blueprint & 267 \\
\hline ID3 & $341-347$ \\
\hline Implementasi TIK & $267,269-271,274$ \\
\hline Indeks TIK & 267 \\
\hline IoT middleware & 335,336 \\
\hline $\mathbf{J}$ & \\
\hline Json & $327,330-332,334$ \\
\hline $\mathbf{K}$ & \\
\hline Kerangka kerja & $257-262,265-266$ \\
\hline Kesuksesan sistem informasi & $315-316$ \\
\hline Klasifikasi & $341-344,346-348$ \\
\hline
\end{tabular}


Jurnal Teknologi Informasi dan Ilmu Komputer (JTIIK), Vol. 6, No. 3, Juni 2019, hlm. 229-348

\begin{tabular}{|c|c|}
\hline K-Means & $321-323$ \\
\hline KNN & $301,303-307$ \\
\hline K-NN & $287-289,292$ \\
\hline Komparasi & 341,347 \\
\hline Kualitas perangkat lunak & 229 \\
\hline \multicolumn{2}{|l|}{ L } \\
\hline LP3SDM AZRA & $309-311,314$ \\
\hline \multicolumn{2}{|l|}{$\mathbf{M}$} \\
\hline Maintainability & $229-233$ \\
\hline Maskapai penerbangan & $321-325$ \\
\hline Metodologi Ward dan Peppard & $245-247,254$ \\
\hline MITM & 335 \\
\hline MVC & $277-281,285-286$ \\
\hline \multicolumn{2}{|r|}{ 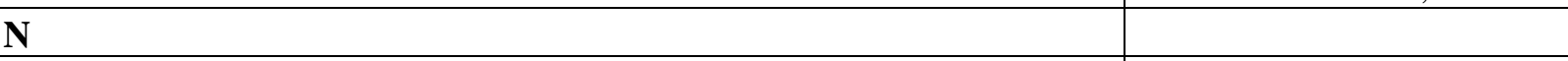 } \\
\hline NAS & $309-314$ \\
\hline Notification api html5 & $327-329$ \\
\hline NWKNN & $301,304-306$ \\
\hline \multicolumn{2}{|l|}{$\mathbf{O}$} \\
\hline Object-oriented & $229-230$ \\
\hline Opini penumpang & $321-322,325$ \\
\hline \multicolumn{2}{|l|}{$\mathbf{P}$} \\
\hline Paperless & $277-281,284-286$ \\
\hline Perencanaan strategis & $245-249,254-255$ \\
\hline Portofolio McFarlan & $245,247,251,253-254$ \\
\hline Pushjs & $327-331,333-334$ \\
\hline \multicolumn{2}{|l|}{$\mathbf{Q}$} \\
\hline Quick response code & $235-236,243$ \\
\hline \multicolumn{2}{|l|}{$\mathbf{R}$} \\
\hline RAD & $277-279$ \\
\hline Raspberry & $309-314$ \\
\hline \multicolumn{2}{|l|}{$\mathbf{S}$} \\
\hline SIE & $257-266$ \\
\hline Sistem informasi & $257-262,266$ \\
\hline Sistem informasi kesehatan & 315 \\
\hline Sistem keamanan mobil & $235-238,240,243$ \\
\hline Smart campus & $267-268,271-274$ \\
\hline Stroke & $287-288,292-293$ \\
\hline \multicolumn{2}{|l|}{ T } \\
\hline Textile & 295 \\
\hline Try out & $277-281,284-286$ \\
\hline \multicolumn{2}{|l|}{$\mathbf{U}$} \\
\hline Understandability & $229-234$ \\
\hline \multicolumn{2}{|l|}{ V } \\
\hline Value chain & $245-250,252-254$ \\
\hline
\end{tabular}


Jurnal Teknologi Informasi dan Ilmu Komputer (JTIIK), Vol. 6, No. 3, Juni 2019, hlm. 229-348

W

Webstorage api html5

$327,329,331$ 
JUDUL ARTIKEL (huruf besar, times new roman, 12pt, tebal, dan ditengah)

(1 baris kosong, 10pt)

Penulis Satu ${ }^{1}$, Penulis Dua ${ }^{2}$ (10pt, tebal, dan ditengah)

(1 baris kosong, 10pt)

${ }^{1}$ Afiliasi Penulis Satu (10pt)

${ }^{2}$ Afiliasi Penulis Dua $(10 \mathrm{pt})$

Email: ${ }^{1}$ penulis.satu@xmail.ac.id, ${ }^{2}$ penulis.dua @xmail.ac.id (10pt)

(1 baris kosong, 10pt)

(Naskah masuk: dd mmm yyyy, diterima untuk diterbitkan: dd mmm yyyy)

(1 baris kosong, 10pt)

Abstrak (10pt, tebal, dan ditengah)

(1 baris kosong, 10pt)

Tempatkan abstrak berbahasa Indonesia pada bagian ini. Abstrak memberikan gambaran umum tentang isi makalah dan harus ditulis dengan Times New Roman 10 dalam format satu kolom. Panjang ideal sebuah abstrak adalah 150 sampai 250 kata. Jika terdapat istilah-istilah asing yang belum dibakukan ditulis italic.

(1 baris kosong, 10pt)

Kata kunci: kata kunci sedapat mungkin menjelaskan isi tulisan, ditulis dengan huruf kecil kecuali singkatan, maksimum enam kata, masing-masing dipisahkan dengan koma, Times New Roman 10pt, italic

(2 baris kosong, 10pt)

JUDUL BAHASA INGGRIS (huruf besar, times new roman, 12pt, italic, tebal, dan ditengah)

(1 baris kosong, 10pt)

Abstract (10pt, italic, tebal, dan ditengah)

(1 baris kosong, 10pt)

Tempatkan abstrak berbahasa Inggris pada bagian ini. Gunakan font Times New Roman 10pt, italic.

(1 baris kosong, 10pt)

Keywords: kata kunci sedapat mungkin menjelaskan isi tulisan, ditulis dengan huruf kecil kecuali singkatan, maksimum enam kata, masing-masing dipisahkan dengan koma, Times New Roman 10, italic

(1 baris kosong, 10pt)

(1 baris kosong, 10pt)

1. PENDAHULUAN (huruf besar, $10 \mathrm{pt}$, tebal)

Jurnal Teknologi Informasi dan Ilmu Komputer (JTIIK) merupakan jurnal yang diterbitkan oleh Fakultas Ilmu Komputer (FILKOM) Universitas Brawijaya, Malang. JTIIK memuat naskah hasilhasil penelitian di bidang Teknologi Informasi dan Ilmu Komputer.

Dokumen ini merupakan template untuk penulisan naskah di JTIIK. Naskah diketik pada kertas berukuran standar A4 (21 cm x 29,7 cm) dalam format dua kolom dan satu spasi. Gunakan margin 3-3-2-2 cm (left-top-right-bottom), lebar tiap kolom 7,5 cm dengan jarak antar kolom $1 \mathrm{~cm}$, menggunakan huruf Times New Roman 10 point dengan spasi tunggal. Pengiriman naskah ke JTIIK harus melalui website yang ada pada alamat http://www.jtiik.ub.ac.id.

Naskah harus ditulis menggunakan Bahasa Indonesia dengan panjang naskah diharapkan tidak melebihi 10 halaman. Penulis diharuskan mengikuti petunjuk penulisan ini dan templatenya bisa didapatkan pada http://www.jtiik.ub.ac.id.

Sistematika naskah adalah: judul yang harus ditulis secara ringkas dan menggambarkan isi naskah, dalam judul hindari penulisan sub judul atau studi kasus; nama penulis (tanpa gelar akademik); afiliasi penulis; alamat email; abstrak (150 - 250 kata) ditulis dalam bahasa Indonesia dan Inggris; kata kunci (minimal tiga buah); pendahuluan yang berisi latar belakang dan tujuan atau ruang lingkup tulisan; metode penelitian yang berisi tentang memformulasikan permasalahan yang diteliti dengan 
lebih rinci (sedapat mungkin ditulis secara matematis) dan menjelaskan metode yang diusulkan; perancangan sistem dimana bagian ini bisa ada atau tidak tergantung kebutuhan; hasil dan pembahasan yang berisi tentang menyampaikan pengujian yang dilakukan dan menganalisis hasil; kesimpulan; daftar pustaka (hanya memuat sumbersumber yang dirujuk).

Isi pendahuluan mengandung latar belakang, tujuan, identifikasi masalah dan metode penelitian, yang dipaparkan secara tersirat (implisit). Kecuali bab Pendahuluan dan bab Kesimpulan, penulisan judul-judul bab sebaiknya eksplisit menyesuaikan isinya. Tidak harus implisit dinyatakan sebagai dasar teori, perancangan, dan sebagainya.

\section{PERSAMAAN MATEMATIKA}

Semua rumus atau persamaan ditulis dengan menggunakan equation editor atau Math Type (http://www.mathtype.com). Penulisan persamaan dimulai pada batas kiri, rata dengan kalimat tepat diatasnya. Jarak baris yang digunakan antara persamaan dengan kalimat diatasnya dan dibawahnya adalah 1,5 (satu setengah) spasi.

Persamaan matematika harus diberi nomor urut dalam kurung biasa dan harus diacu dalam tulisan. Persamaan matematika dinomori dengan angka Arab di dalam tanda kurung buka-tutup pada posisi rata kanan kolom. Untuk persamaan yang tidak cukup ditulis dalam lebar 1 kolom, penulisannya dapat melintasi 2 kolom, ditulis di bagian bawah halaman dan diberi nomor urut yang sesuai. Simbol didalam persamaan harus didefinisikan dan dapat dituliskan sebelum atau setelah persamaan. Persamaan (1) merupakan contoh penulisan persamaan untuk mencari frekuensi baud rate mode dua pada komunikasi serial mikrokontroler 8051.

Pada persamaan (1), $f_{\text {baud }}$ merupakan frekuensi baud rate. SMOD adalah bit control dalam PCON (Power Mode Control Special Function Register), sedangkan foSC merupakan frekuensi oscillator/Kristal yang digunakan dalam rangkaian mikrokontroler.

$f_{\text {baud }}=\frac{2^{S M O D}}{64} x f_{\text {osC }}$

\section{TABEL DAN GAMBAR}

Semua tabel dan gambar harus jelas/tidak kabur/buram. Ukuran huruf pada tabel dan gambar harus dapat dibaca oleh mata normal dengan mudah. Posisi tabel atau gambar disuatu halaman, sebaiknya terletak dibagian atas atau bawah halaman pada tiap kolom. Contoh dapat dilihat pada tabel 1 atau gambar 1. Meletakkan tabel atau gambar ditengah halaman atau paragraf supaya dihindari. Tabel dan gambar diletakkan pada posisi tengahsetiap kolom (center alignment).

\subsection{Penulisan Tabel (10pt, tebal)}

Nomor dan judul tabel ditulis diposisi tengah kolom (center alignment). Tabel dinomori dengan angka arab sesuai dengan urutannya. Judul tabel ditulis dibagian atas tabel dengan cara title case, kecuali untuk kata sambung dan kata depan. Ukuran huruf untuk judul tabel dan isi tabel adalah 8 (delapan). Sisi paling luar tabel tidak boleh melebihi batas margin kolom. Jika ukuran tabel tidak cukup ditulis dalam lebar 1 (satu), maka penulisannya dapat melintasi 2 kolom. Jarak baris yang digunakan antara tabel dengan kalimat diatasnya dan dibawahnya adalah 1 (satu) baris kosong. Tabel wajib menggunakan layout sesuai dengan Tabel 1 tanpa menggunakan garis lurus/vertikal. Setiap tabel harus diacu dalam tulisan dengan disertai nomor tabel dan diawali dengan huruf besar, misalnya Tabel 1.

\subsection{Penggunaan Gambar}

Nomor dan judul gambar ditulis diposisi tengah kolom (center alignment). Nomor gambar ditulis sesuai dengan urutannya menggunakan angka arab. Judul gambar ditulis dibagian bawah gambar dengan cara title case, kecuali untuk kata sambung kata sambung dan kata depan. Judul gambar menggunakan ukuran huruf 8 (delapan). Gambar tidak boleh melebihi batas margin dari tiap kolom, kecuali jika ukuran gambar yang besar tidak cukup dalam 1 kolom, maka dapat melintasi 2 kolom.

(1 baris kosong, 10pt)

\begin{tabular}{ccc} 
Tabel 1. Rancangan Analisis Komputasi (8pt, ditengah) \\
\cline { 2 - 3 } mesin & operasi & waktu(menit) \\
\hline 1 & 5 & 10 \\
& 4 & 12 \\
& 4 & 16 \\
2 & 3 & 18 \\
& 4 & 20 \\
\hline
\end{tabular}
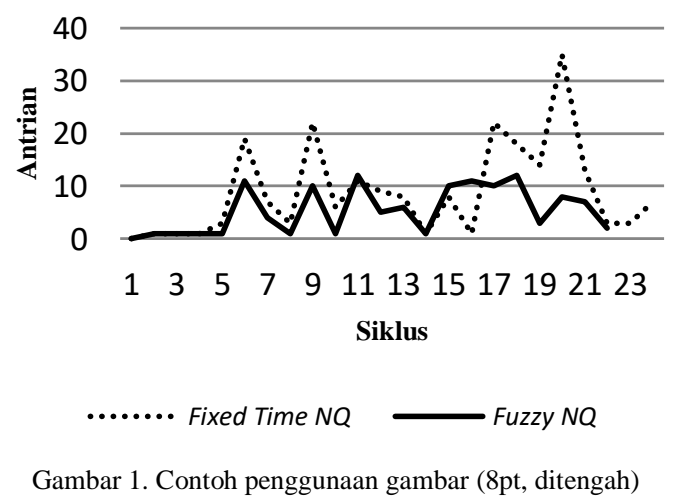

(1 baris kosong, 10pt)

Jarak baris yang digunakan antara gambar dengan kalimat diatasnya dan dibawahnya adalah 1 (satu) baris kosong. Usahakan gambar tidak berwarna/hitam putih (kecuali penggunaan warna pada gambar sangat diperlukan/tidak bisa dihindari) 
dan jika dicetak dalam hitam putih bisa dibedakan. Jika gambar berupa grafik harus jelas perbedaan antara satu sama lain dengan menggunakan jenis line dan marker yang berbeda-beda. Setiap gambar harus diacu dalam tulisan dengan disertai nomor gambar dan diawali dengan huruf besar, misalnya Gambar 1 .

\section{SUMBER PUSTAKA/RUJUKAN}

Sumber pustaka/rujukan sedapat mungkin merupakan pustaka-pustaka terbitan 5 tahun terakhir. Pustaka yang diutamakan adalah naskahnaskah penelitian dalam jurnal, konferensi dan/atau majalah ilmiah. Pustaka lain dapat berupa buku teks atau laporan penelitian (termasuk Skripsi/Tugas Akhir, Tesis, dan Disertasi), akan tetapi diusahakan tidak melebihi $20 \%$ dari seluruh jumlah sumber pustaka.

Penulisan sumber pustaka dan cara mengacu menggunakan aturan Harvard-Anglia dengan sedikit modifikasi dalam penulisan nama penulis didaftar pustaka menggunakan huruf besar semua. Beberapa aturan tentang penulisan sumber pustaka, yaitu: sumber pustaka yang ditulis dalam daftar pustaka sebelumnya harus pernah diacu dalam naskah, ditulis berurutan secara alfabetis tanpa nomor, apabila ada beberapa sumber pustaka mempunyai penulis sama maka diurutkan berdasarkan tanggal terbitnya, dan apabila ada beberapa sumber pustaka mempunyai penulis sama pada tahun penerbitan yang sama juga maka diurutkan dengan menambah huruf kecil ditahun publikasi (2011a, 2011b, 2011c).

Petunjuk lebih lengkap mengenai aturan Harvard-Anglia dapat dibaca pada link http://www.citethisforme.com/guides/harvardanglia-ruskin-university/. Beberapa contoh penulisan sumber pustaka dapat dilihat dibagian Daftar Pustaka.

Sebagai contoh cara menulis daftar pustaka yang mengacu pada jurnal. Elemen yang harus ditulis pada daftar pustaka adalah:

NAMA BELAKANG PENULIS, INISIAL., Tahun. Judul artikel. Judul jurnal, Nomor volume (Nomor/tipe keluaran), No halaman. Tempat publikasi:Penerbit.

Elemen yang harus ditulis pada saat mengacu adalah: Nama penulis diikuti dengan tahun publikasi. Dalam daftar pustaka tertulis:

BROUGHTON, J.M., 2002. The Brettow Woods proposal: a brief look. Political Science Quarterly, 42(6), p.564.

COX, C., BROWN, J.T. dan TUMPINGTON, W.T., 2002. What health care assistants know about clean hands. Nursing Today, Spring Issue, pp.64-68.
Saat mengacu dalam teksnya yang harus ditulis adalah:

...(Broughton, 2002).

...(Cox, Brown, \& Tumpington, 2002).

\section{ATURAN LAIN}

Semua naskah ditelaah secara double blindreview oleh mitra bestari (reviewers) yang ditunjuk oleh editor menurut bidang kepakarannya. Penulis naskah diberi kesempatan untuk melakukan perbaikan (revisi) naskah atas dasar rekomendasi/saran dari mitra bestari dan editor. Kepastian pemuatan atau penolakan naskah akan diberitahukan secara tertulis melalui email.

Pemeriksaan dan penyuntingan cetak-coba dikerjakan oleh redaksi dan/atau dengan melibatkan penulis. Naskah yang sudah dalam bentuk cetakcoba dapat dibatalkan pemuatannya oleh redaksi jika diketahui bermasalah.

Segala sesuatu yang menyangkut perijinan pengutipan atau penggunaan software komputer untuk pembuatan naskah atau hal lain yang terkait dengan HAKI yang dilakukan oleh penulis naskah, berikut konsekuensi hukum yang mungkin timbul karenanya, menjadi tanggung jawab penuh penulis naskah tersebut.

\section{DAFTAR PUSTAKA}

ALIF, A., 2013. Komputasi cerdas untuk pemula. Malang: ABC Press.

BERNDTSSON, M., HANSSON, J., OLSSON, B. \& LUNDELL, B., 2008. Thesis projects: a guide for students in Computer Science and Information Systems. 2nd ed. London: Springer-Verlag London Limited.

BROUGHTON, J.M., 2002a. The Brettow Woods Proposal: a Brief Look. Political Science Quarterly, 42(6), p.564.

BROUGHTON, J.M., 2002b. The Brettow Woods Proposal: a Brief Look. Political Science Quarterly, [e-journal] 42(6). Tersedia melalui: Perpustakaan Universitas BX <http://perpustakaan.ubx.ac.id> [Diakses 1 Juli 2013]

CAKRANINGRAT, R., 2011. Sistem pendukung Keputusan untuk UMKM. [ebook]. UBX Press. Tersedia melalui: Perpustakaan Universitas BX <http://perpustakaan.ubx.ac.id> [Diakses 1 Juli 2013]

COX, C., BROWN, J.T. dan TUMPINGTON, W.T., 2002. What Health Care Assistants Know about Clean Hands. Nursing Today, Spring Issue, pp.64-68.

GOALIE, D. 2008. Remote Sensing Technology for Modern Soccer. Popular science and Technology, [online] Tersedia di: 
4 Jurnal Teknologi Informasi dan Ilmu Komputer (JTIIK), Vol. x, No. x, April 2014, hlm. x-y

<http://www.popsci.com/b012378/soccer.ht ml> [Diakses 1 Juli 2009]

International Standards Office, 1998. ISO $690-2$ Information and Documentation: Bibliographical References: Electronic Documents. Geneva: ISO.

RICHMOD, J., 2005. Customer Expectations in the World of Electronic Banking: a Case Study of the Bank of Britain. PhD. Anglia Ruskin University.

RUMBAUGH, J., JACOBSON, I. \& BOOCH, G., 2005. The Unified Modeling Language reference manual. 2nd ed. Boston: Addison-Wesley.

SAMSON, C., 1970. Problems of information studies in history. Dalam: S. Stone, ed. 1980. Humanities information research. Sheffield: CRUS.pp. 44-68.

Scottish Intercollegiate Guidelines, 2001. Hypertension in the elderly. (SIGN publication 20) [online] Edinburgh: SIGN (Diterbitkan 2001) Tersedia di:<http://www.sign.ac.uk/sign49.pdf> [Diakses 22 November 2004]

SOMMERVILLE, I., 2011. Software engineering. 9th ed. London: AddisonWesley.

TANENBAUM, A.S., 1998. Organisasi Komputer Terstruktur, jilid 1. Diterjemahkan dari Bahasa Inggris oleh T.A.H Al-Hamdany. 2001. Jakarta: Salemba Teknika.

UNDESA (United Nations Department of Economic and Social Affairs), 2005. 6th Global forum for reinventing government: towards participatory dan transparent governance. Seoul, Republic of Korea, 24-27 May 2005. New York: United Nations.

Undang-undang Republik Indonesia nomor 12 tahun 2012 tentang Pendidikan Tinggi. Jakarta: Kementerian Sekretariat Negara Republik Indonesia. 


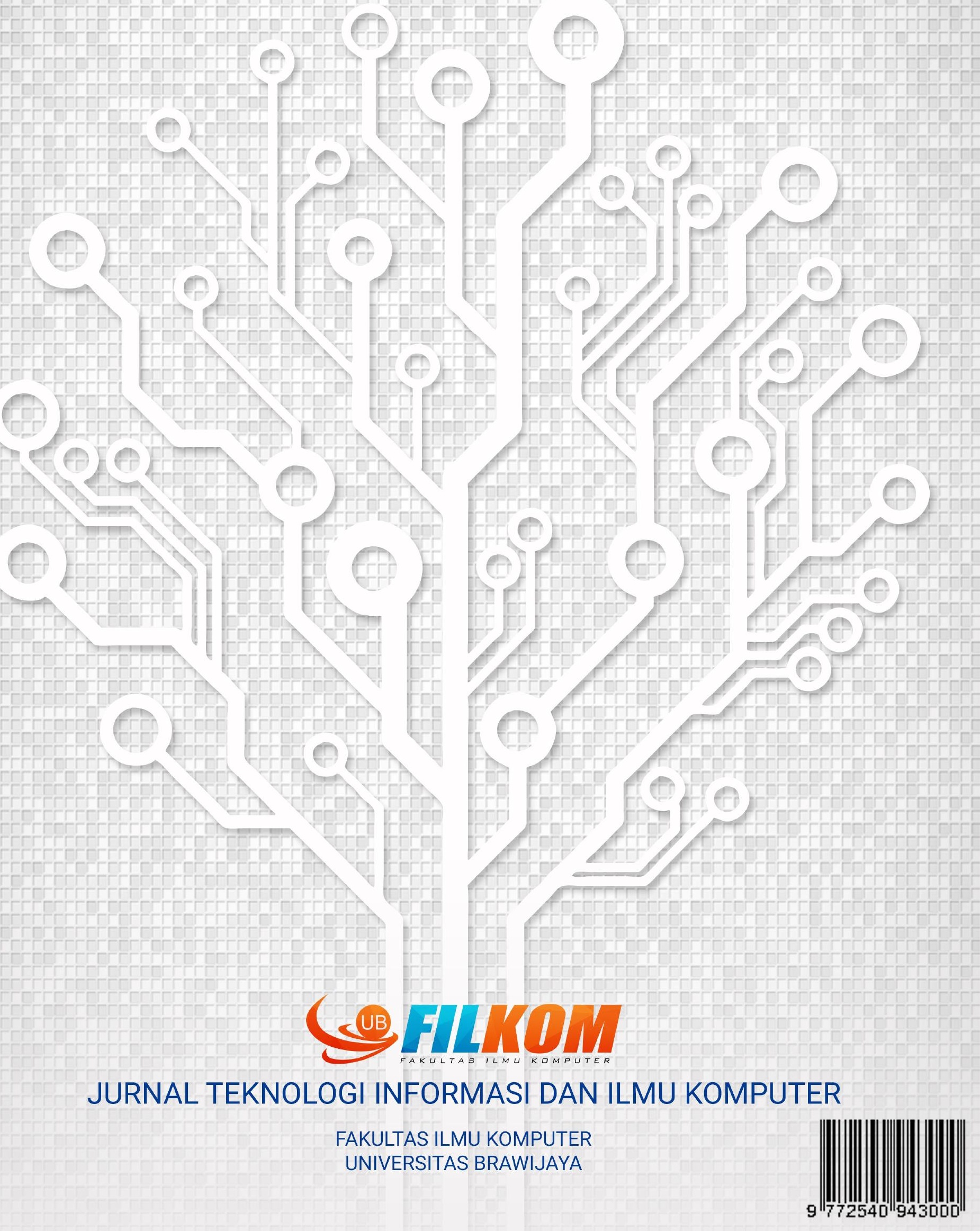

